\title{
Review: Agriculture-industry linkage and technology adoption in Ethiopia: Challenges and opportunities
}

\author{
TILAHUN SISAY \\ Science, Technology and Information Communication Commission, Amhara National Regional State (ANRS), Ethiopia P.O.Box.2276, Bahir Dar, \\ Ethiopia. email: tilahunsisay80@gmail.com
}

Manuscript received: 19 May 2018. Revision accepted: 8 June 2018.

\begin{abstract}
Sisay T. 2018. Review: Agriculture-industry linkage and technology adoption in Ethiopia: Challenges and opportunities. Trop Drylands 2: 18-27. High rate of agricultural growth has far-reaching positive implications for economic development of low-income countries in terms of increasing employment and accelerating poverty reduction. For Ethiopia to achieve middle-income status by 2025 and make substantial inroads against food insecurity, concerted and strategic investment and strategic choices in the agricultural sector are vital. Agricultural linkage encloses generating and transferring agricultural technologies to enhance productivity, reduce loss, and improve the livelihoods of beneficiaries as well as the country's economy. The objective of this paper was to review the current status of linkage between agriculture-industry actors, extent of technology adoption system, challenges and opportunities in Ethiopia. The result of the review study shows that different factors are constraining the system. Most of the agriculture industry linkage and technologies promoted through the extension system and adoption levels are far below the possible expectation in the country. Agriculture research institutions and industries lack effective mechanisms of transferring their technologies to the end users, inadequate technological skilled manpower, poor market linkage between technology multiplication enterprises and technology users and lack of responsible body to transfer technology which becomes the major challenges in Ethiopia. Factors constraining the linkage between stakeholders and technology adoption level of universities, TEVTs, agriculture research institutions, and agriculture sector are wide-ranging from poor linkage between stakeholders and weak involvement of professionals are among the main problems that constrain the system. Weak link between research, education, and extension and the contact these organizations have with farmers is among the main bottlenecks in agricultural technology development, adoption level. Therefore, strong university and research-industry linkage are needed in the country.
\end{abstract}

Keywords: Adoption, linkage, challenges, opportunities, technology

\section{INTRODUCTION}

Agricultural information is necessary for decisionmaking, and a resource that must be acquired and used to make an informed decision (Kaske 2007). Information and knowledge are powerful engine for development, but the attributes of information largely depend on the effective application of the information and the overall package of the technology. Improved agricultural technologies are central to transformation of farming systems and a path out of poverty in developing countries (Besley and Case 1993). In Sub-Saharan African (SSA) countries where agriculture is the predominant sector that underpins the livelihood of the majority of the poor, increasing technology adoptions, such as new agricultural practices, high-yielding varieties and the associated products such as crop insurance, have the potential to contribute to economic growth and poverty reduction among the poor (Kelsey 2011).

The pathway out of poverty trap of many SSA countries depends on growth and development of the agricultural sector. The main objective of the sustainable development goals is eradicating extreme poverty, hunger and investing in rural areas for inclusive and sustainable rural transformation. This is possible by increasing agricultural productivity through yield-increasing technologies in order to sustain food self-sufficiency. For many years, the government of Ethiopia has been working with extension programs in diffusing agricultural technologies to improve smallholders' crop productivity and farmers' income through surplus crop production. Paradoxically, recent study indicates that farmers' use of main agricultural inputs such as high-yielding varieties is less than 5\% (Taffes et al. 2013). The low adoption rate and use can be partly explained by limited access to input credit (ATA 2014).

Agricultural system performance can be improved by having strong linkage between research, education, extension, farmer and other stakeholders. The aims of agricultural linkage enclose generating and transferring agricultural technological packages to enhance productivity, reducing loss, and improving the livelihoods of the beneficiaries in particular and the countries' economy in general. In the last decades, agricultural information has increased rapidly, however, the effective transfer of agricultural information/knowledge is still a big challenge. The main factors affecting the effective transfer of agricultural technological packages to the end-users are knowledge level of the information users, access to information of end users, and readiness of farmers for adoption (Taffes et al., 2013). 
Ethiopia has many problems in balancing economic growth as the human population grow rapidly. Therefore to solve these problems, the linkage of agriculture with industry and technology adoption is of great importance. Imbalance between the population growth rate and the agricultural production growth rate is one of the pronounced national problems in Ethiopia and at subnational level such as Amhara Region. Low-level productivity due to low level of improved technologies utilization and high risk due to adverse environment are among the most frequently mentioned major causes of the country's chronic food security problem. In order to meet the food requirements of the growing population, food grains and other agricultural products have to be increased. The immediately available means to attain the national goal of food self-sufficiency is improving productivity through improved technologies. Improved seeds, fertilizer, farming tools, pesticides, etc. are some of the major productivityenhancing inputs.

Various factors contribute to the low productivity of the agricultural sector in the country. Of all the barriers, the low level of agricultural technology development and innovative technological package transfer system by smallholder farmers are among the important factors (Kassa 2003). Although agricultural extension has long history in Ethiopia, the coverage is very low and the linkage of the actors of the system is very poor, which is the main reason for low adoption of improved agricultural technology/production systems and inputs (Kassa 2003). The problem of weak linkages, existing gaps and poor inter-organizational relations still exist (Belay 2003). This calls for improvement of the linkage between the different stakeholders of the sector and adoption level so as to improve the livelihoods of smallholder farmers in particular and nations in general. Therefore, the main purpose of the current review study was to assess the status of the existing link between agriculture and industries, technology adoption of the institutions so as to indicate the future intervention areas in the country.

\section{AGRICULTURE AND INDUSTRY LINKAGE IN ETHIOPIA}

\section{Ethiopian agriculture development for growth}

For Ethiopia to achieve middle-income status by 2025 and make substantial inroads against food insecurity, concerted and strategic investment and strategic choices in the agricultural sector are vital. Concentrations of food insecurity and malnutrition are endemic in rural areas, with a population of six to seven million chronically food insecure, and up to 13 million seasonally food insecure. Over $90 \%$ of agricultural output is driven by smallholder farmers. Without expanding the cultivated lands, and given forecast population growth, the average landholding size in highland areas will be reduced to 0.7 ha by 2020, placing further pressure on rural incomes and food security. Agriculture contributes substantially to the overall Ethiopian economy. On a nominal GDP of USD 25.6 billion (World Bank, 2008), 43\% was driven by the agricultural sector. Crop production accounts for $29 \%$, with livestock at $12 \%$, followed by the forestry sector with 4 percent. The sector contributed USD 1.4 billion to export earnings with crops and forestry account for $60 \%$ of overall export value, livestock for $28 \%$, and the remaining exports is a combination of non-agricultural industry, primarily extractives and industrial production.

\section{Agricultural growth as a driver of development}

A high rate of agricultural growth has far-reaching positive implications for economic development of lowincome countries in terms of increasing employment and accelerating poverty reduction. High agricultural growth also helps avoid the creation of mega-cities with large slum populations. In order to achieve this rapid agricultural growth with positive economy-wide linkages, however, it is necessary to engage medium-scale farmers, i.e. large enough to adopt new technologies and produce significant marketed surpluses, but small and numerous enough to have spending patterns that drive a vibrant rural non-farm sector. Finally, public and private investments in road, electricity and telecommunications are also needed to reduce marketing costs and enable growth in rural market towns and secondary cities (Stiglitz 2009).

\section{Agricultural development as an input to the industry}

Agriculture is the mainstay of Ethiopia's economy. According to the Food and Agriculture Organization (FAO) and the World Food Program (WFP), agriculture sector contributes about $45 \%$ to $50 \%$ of GDP and provides employment to nearly $80 \%$ of the country's population. Its growth is vital to the national economic development and well-being of the population. It produces a wide variety of products. The Government of Ethiopia drew up a long-term industrial strategy in 1994 known as Agricultural Development-Led Industrialization (ADLI). The Government is convinced that agriculture is the engine that can propel the socio-economic development of Ethiopia by providing the basis for industrialization and necessary surplus for the expansion of other sectors of the economy. The ADLI strategy gives priority to the development of agriculture as a primary stimulus for the sustainable growth of agro-industry and is expected to raise productivity in both agriculture and agro-industry through appropriate linkages between the two sectors (i.e. agriculture and industry) as well as management, technology, human resources and various incentive mechanisms. Unfortunately, seven years after the ADLI strategy was formulated, agriculture remains essentially undeveloped. Agricultural research, in particular, which is the backbone of the development and sustainable growth of the sector, does not seem to benefit from the support it needs from agro-industries (FDRE and MOFE 2002).

Agriculture is the foundation of the national economy and plays a major role in the socio-economic development of the country. The government launched the agricultural Development-led industrialization strategy where emphasis is put on linking research with development through wellfocused and targeted transfer of appropriate technology to farmers. The agricultural development strategy is aimed at 
promoting growth, reducing poverty and attaining food self-sufficiency while protecting the environment through safe use of improved technologies. The agricultural package program is spearheaded through demonstration and provision of improved varieties and required inputs such as improved seeds, fertilizers, and pesticides as well as better access to credit facilities (ICARDA et al. 1999). Moreover, Agricultural Development Led Industrialization (ADLI) sets out agriculture as a primary stimulus to generate increased output, employment and income for the people, and as the springboard for the development of the other sectors of the economy. A 'green revolution'-like intensification of smallholder agriculture was seen as central by the government in implementing the strategy (Keeley and Scoones 2000).

\section{Agricultural Development Led Industrialization (ADLI) and food security in Ethiopia}

ADLI is seen as a long-term strategy to achieve faster growth and economic development by making the use of technologies that are labor using, but land augmenting, such as fertilizer and improved seeds and other cultural practices. During the first stage of ADLI, agriculture is aimed to play a leading role in the growth of the economy. But the extremely small ratio of urbanization of the country threatens to make inadequacy of domestic demand a critical constraint. This implies that agriculture has to be made internationally competitive, and that part of its production has to be oriented towards exports. For agriculture to continue serving as an engine of growth in the coming years, through the domestic economy and international trade, there has to progress in terms of commercialization, with more intensive farming, increasing proportion of marketable output and correspondingly decreasing ratio of production for own consumption. Aside from deepening technological progress, it will mean greater market interaction on the part of the farmer. Extension of credit to the small farmer will gain importance with commercialization of agriculture, and give impetus to the establishment of rural banks. Cooperatives play important roles in facilitating input and output marketing as well as in promoting the provision of rural finance. The problem of food security and agricultural growth in pastoral areas is being conceived in terms of the development of the pastoral economy in its entirety (FDRE and MOFE 2002).

Unless industry (secondary-modern goods-producing sectors) and services (tertiary-distributive and other services) grow in conjunction with agriculture (primary agriculture and allied activities), it is not possible to ensure accelerated growth and sustainable development. In an agrarian economy such as Ethiopia, the resources for the development of the industrial sector need to be generated by primarily creating strong bondage between agriculture and industry and subsequently exploiting these linkages via the concerted efforts of non-state actors, particularly the non-peasant private sector (FDRE and MOFE 2002). Core of ADLI are increasing agricultural output and productivity, increasing industrial output and productivity, and close input-output linkage between the two sectors (Figure 1).

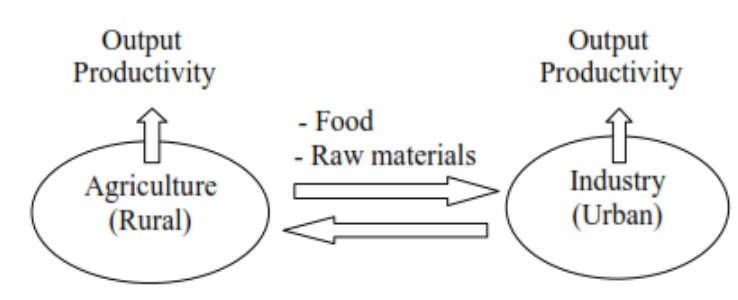

Figure 1. Commercialization of agriculture (left side); machinery, fertilizer, other agriculture inputs, consumption goods and export orientation, labor intensiveness (right side)

\section{Formulation of Agricultural Development Led Industry (ADLI)}

An Economic Development Strategy for Ethiopia (1994) implies productivity improvement of smallholder agriculture and industrialization based on utilization of domestic raw materials with labor-intensive technology. The strategy is akin to what is known as ADLI, framed into the Ethiopian context. Two-pronged approaches include: (i) Smallholder agriculture - better agronomic practices, more labor use, research and extension, technology transfer, rural infrastructure; (ii) Extensive mechanized agriculture and intensive farming - efficient land allocation, labor supply, health and road facilities for new lands, research and training, quality, marketing, etc. Besides direct input-output links (Core ADLI), the two sectors may have the following links, which may occur directly through financial system (Figure 2).

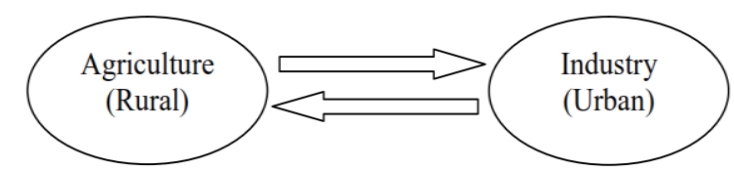

Figure 2. Labor supply, agro/land tax, price control, export earnings (left side); and production support, food and service delivery, agricultural protection, public investment (right side)

\section{AGRICULTURAL LINKAGE AND TECHNOLOGY INNOVATION SYSTEM IN ETHIOPIA}

\section{Definition of technology}

Any definition of technology encompasses a wide range of phenomena. In the broadest sense, technology is defined as the translation of scientific knowledge into machines, tools, mechanical devices, instruments, innovation, procedures and techniques to accomplish tangible ends, attain specific needs, or manipulate the environment for practical purposes (Shahin 2004). New agricultural technology is generally a bundle or package of different technological elements, such as improved production and productivity, plus the technical practices and skills needed for their effective use (SAMY 1998; Shahin 2004).

\section{Linkages and linkage mechanisms}

According to Hagmann et al. (2002), linkages between service providers and service delivery systems are critical to 'make the system work as a system'. To bring sustainable 
agricultural development, partners within the sector must develop joint collaborative action to ensure efficient and effective input/service delivery system. To support actors in the sector, the Regional Research Extension, Farmers Linkage Advisory Council (REFLAC) started to strengthen the linkage among multiple actors. Potential actors like BoARD, Research stations, and FREG have participated in joint planning for action. The main aim of the council is to promote farmers participatory research through strong collaborative action by potential actors and to develop areaspecific technologies through adaptation trials and farmersto-farmers' seed exchange specifically on cereal and pulse crops. The Regional Rural Capacity Building Project (RCBP) is in charge of facilitating joint activities carried out by partners through budget and material support, i.e., capacity building, workshops, joint monitoring, and evaluations, for members of advisory council and FREG.

\section{Linkages between technology and agriculture}

Generation of technology is not an end by itself. It must be utilized by end-users. This can be realized through the presence of effective linkage among the major stakeholders in agriculture, agricultural knowledge, and information system. Linkages between major institutional actors in agricultural knowledge and information system are widely recognized as essential for an effective flow of technology and information between research, extension, and farmers. The types and nature of linkage between actors within the agricultural knowledge and information system directly influence the production and productivity of smallholder farmers. It is commonly recognized by agricultural knowledge and information system stakeholders that poor performance of the system is often related to linkage problems (Akalu and Adgo 2006).

Linkages and linkage mechanisms can be strong or sometimes poor or not working. The reasons for poor linkages are weak management capacity, inappropriate organizational structure, unfavorable reward systems, time and money constraints, inappropriate planning, little or no monitoring and evaluation of the process of interaction and different organizational cultures, expectations and operating procedures. Therefore, inter-organizational linkages should be assessed to maintain better aspects and negotiate improvements in existing linkages, linkage mechanisms and develop new relationships. Decisive factor that can influence the effectiveness of linkages includes intensity and formality of contacts, ways of contacts (one way or two), stakeholders' awareness of other stakeholders function, relevance of services, urgency, timeliness, accessibility, quality of communication, control over the relationship, and mandate of representatives (ICRA 2010).

\section{Causes of poor adoption by agriculture industry of technologies}

The majority of the agriculture industries do not link with local agriculture research industries which is a sign of serious disarticulation of the national system of innovation in Ethiopia. This situation is a serious constraint to the adequate growth of both agriculture and agro-industry in the country (Akalu and Adgo 2006). The slight improvement in the co-operation between agriculture industries and agriculture research industries after 1999 may be ascribed mainly to the awareness created through a workshop organized by EARO in November 1999.

Factors preventing the agriculture industries from forging links with local agriculture research industries are varied. Lack of information is the most overwhelming challenge as indicated by $74 \%$ of agriculture-industries that do not have any kind of collaboration with the agriculture research industries. According to $51 \%$ of the noncollaborating agriculture-industries, the second most important challenge is the poor relations between the agriculture-industries and local agriculture research industries. Only $11.4 \%$ of the non-collaborating agriculture-industries indicates that the technologies developed by local agriculture research industries either fail to respond to their needs or are irrelevant to the agriculture-industries. Agriculture research industries lack effective mechanisms of transferring their technologies to the end-users. They are not successful in communicating effectively with agriculture-industries and most likely with farmers and, therefore, do not take appropriate actions that are conducive to the adoption of their technologies (Hagmann et al. 2002).

\section{ADOPTION OF NEW TECHNOLOGIES}

Adoption is referred to as the degree of use of new technology in long-run equilibrium when a farmer has all the information about the new technology and its potential. Adoption refers to the decision to use new technology, method, practice, etc. by a firm, farmer or consumer. Adoption of the farm level (individual adoption) reflects the farmer's decisions to incorporate new technology into the production process. On the other hand, aggregate adoption is the process of spread or diffusion of new technology within a region or population. Therefore, a distinction exists between adoption at the individual farm level and aggregate adoption, within a targeted region or within a given geographical area (Feder et al. 1985).

Adoption of technological innovations in agriculture has attracted considerable attention among development economists because the majority of the population of less developed countries derives their livelihood from agricultural production and new technology, which apparently offers opportunities to increase production and productivity (Feder et al. 1985). Agriculture progresses technologically as farmers adopt innovations. The extent to which farmers adopt available innovations and the speed by which they do so determines the impact of innovations in terms of productivity growth (Diederen et al. 2003). If innovation is modified periodically, however, the equilibrium level of adoption will not be achieved. This situation requires the use of econometric procedures that can capture both the rate and the process of adoption (Getahun et al. 2000). 


\section{Process of agricultural technology adoption in developing countries}

Literature on agriculture highlights two major drivers of successful agricultural technology adoption in developing countries: (i) the availability and affordability of technologies; and (ii) farmer expectations that adoption will remain profitable - both of which determine the extent to which farmers are risk-averse (Foster and Rosenzweig 2010). A number of factors drive the above expectations, ranging from availability and size of land, family labor, prices and profitability of agricultural enterprises, and peer effects. The conceptual framework presented here highlights the various pathways through which different factors influence household decisions to adopt agricultural technologies.

Based on extensive studies in Ethiopia, it has been shown that life-cycle effects are important drivers of agricultural technology adoption (Admassie and Asfaw 2004). In particular, younger as well as much older household heads are risk-averse and are less likely to adopt new technologies. On the other hand, the availability of adult family members within households may facilitate the process of technology because most farming households cannot easily acquire hired labor due to liquidity constraints.

\section{Drivers for adoption of agricultural technologies and practices in Ethiopia}

Adoption of improved technologies offers a myriad of potential advantages for increasing productivity and income for smallholder farmers. However, none of these advantages are single or immediate drivers for adoption of agricultural technologies by smallholders. Rather, there are many pushes and pull factors that force, encourage or discourage households to use improved technologies. Various models and approaches have been attempted and tested to identify drivers of adoption of technologies by potential clients (Zaltman et al. 1973; Rogers 1995). Some schools of thought approach the issue by combining the clients, technology attributes, and institutional factors (Solomon et al. 2011) to understand the drivers of adoption and what factors drive its speed of diffusion and the path it follows.

Understanding adoption remains a challenge and drivers of adoption are poorly understood. Studies have shown that the misconception of adoption prevails both at micro level where technologies are promoted and at vertical scaling where technologies are generated in institutional settings (Doss 2006). Different studies have been conducted on adoption of agricultural technologies in Ethiopia (Alemitu 2011; Hailu et al. 2014). However, many of them focused on a single commodity or technology and did not consider the possible inter-relationships between the various practices and intensity of adoption of a package of technologies. Agricultural technologies include all kinds of improved techniques and practices that affect the growth of agricultural output. The technologies and practices that were assessed for adoption are a selection of extension packages as promoted by the extension system and implemented at grass root levels. Four agricultural technologies have been considered for developing a new adoption index for crop technology. These include (i) seeds of high-yielding varieties, (ii) inorganic fertilizers, (iii) pesticides, and (iv) row seeding. Similarly, to assess dairy technology adoption, a composite index of improved breed dairy cow ownership, improved feed and forage utilization and use of Artificial Insemination (AI) services was employed.

Empirical review of the literature on technology adoption in developing countries reveals that the various factors that influence technology adoption can be grouped into the following three broad categories. Firstly, the factors related to the characteristics of producers, i.e., the farmers include: education level, experience with the activity, age, gender, level of wealth, farm size, plot characteristics, labor availability, resource endowment, risk aversion, etc. Secondly, the factors related to the characteristics and performance of the technology and practices include: food and cash generation functions of the product, the perception by individuals of the characteristics, complexity and performance of the innovation, its availability and that of complementary inputs, the relative profitability of its adoption compared to substitute technologies, the period of recovery of investment, local adoption patterns of the technology, the susceptibility of the technology to environmental hazards, etc. Thirdly, the institutional factors include: availability of credit, the availability, and quality of information on the technologies, accessibility of markets for products and inputs factors, the land tenure system, and the availability of adequate infrastructure, extension support, etc. Enabling policies and programs, market linkages, access to institutional support and credit were found to play a positive role in stimulating farmer investment in and adoption of sustainable technologies (Shiferaw et al, 2009). A fourth category is a biophysical environment that many studies also find to be an important conditioning factor in adoption of agricultural technologies (De Graaff et al. 2008; Solomon et al. 2012).

\section{The importance of adoption of new technologies}

The increasing complexities of environmental problems are likely to increase the necessities of new agricultural technologies that can be used to minimize the potential contribution of negative environmental consequences of agricultural production. Climate change will affect crop and livestock yields worldwide, which will lead to change in food and fiber consumption, prices of agricultural commodities, and farm income (USDA 2014). Technology adoption practices can include good agrarian practices, irrigation scheduling, conservation tillage, organic farming, erosion reduction, nitrogen fertilization and plastic-covered horticulture (Bertuglia et al. 2006).

A study by Maredia and Minde (2002) explored the relationship between profitability of Agricultural technologies and their adoption by farmers in Eastern Africa. The study showed that some profitable technologies, such as improved cassava varieties in Uganda and improved coffee varieties in Kenya, were adopted. Some other technologies that were not fully adopted or had been restricted to on-farm demonstration plots included wheat variety and hybrid maize in Ethiopia and the application of inorganic fertilizer on maize in Kenya. The lower adoption level was related to non-technological 
constraints (e.g. infrastructure, policies, input/output markets, and adverse climatic conditions) which reduced profitability and adoption of new technologies. For this reason, there is a need for continuous efforts to supply technologies that are adapted to the prevailing environmental conditions.

\section{Factors affecting adoption}

Technology adoption is important because it is a means that allows people to participate in a rapidly changing world where technology has become crucial to their lives. The word "adoption" refers to the stage in which technology is selected for use by an individual or an organization. Besides, technology users differ widely in their attitudes towards technology. According to this source, technology adoption consists of four steps: First, technology adoption requires awareness. At this step, the potential users get adequate information about the benefits of the technology. The second step is assessment. At this level, the expected users evaluate the usefulness and usability of the technology, and the ease or difficulty of adopting. This is followed by acceptance or refusal of the users. At this stage, they decide to acquire and use the technology, or not. The fourth stage is learning. If they decide to use the technology, the users need to develop the skills and knowledge required to use the technology effectively. A study by Gabre-Madhin and Haggblade (2001) found that large commercial farmers adopted new high-yielding maize varieties more rapidly than small farm holders.

Koundouri et al. (2002) argue that farmers' decision to adopt new technology is affected by risk factors that are related to production risk and how the new technology can change the amount of production and profitability of the farmers. Kosarek et al. (2001) also found that farmers' decision to adopt hybrid maize was determined by the expected returns (i.e., profitability) of the technology, the availability of hybrid seed, and risks associated with the expected outcomes of the new technology. The role of factors that influences adoption decisions is critical to successful agricultural development. Different factors determine the adoption of different agricultural innovations and technologies. Beliefs and perceptions of farmers, communities, and absence of institutional innovations have impact on adoption decisions. There are risk and uncertainty factors for small-scale farmers in adopting new technologies.

\section{STAKEHOLDERS IN RURAL INNOVATION IN AMHARA REGION}

\section{Stakeholders involved in different rural innovation activities}

Technology generation, technology experimentation, technology diffusion, technology learning and training, input supply, value addition, and financial support in Amhara Regional State are mapped in (Figure 3). The stakeholders are mapped according to the scale of involvement (user group, local, regional and national) and the role they play in rural innovation. It was found that the level of stakeholders involved in technology generation in Amhara Region ranged from national to regional level. However, there was no stakeholder involved in technology generation at district and zone levels, except at farmer level, where focus was given to technology experimentation and diffusion (ICRA 2010). Most of the stakeholder organizations were involved in technology learning and training at different levels followed by those involved in technology generation and diffusion. The number of stakeholder organizations involved in value addition (agroprocessing) is very few, followed by those involved in input supply and financial services (Figure 3). In fact, Amhara Region is one of the regions in the country where there is surplus agricultural production, although there are areas in the region that are not yet self-sufficient. The results suggest that although the region could increase its production and productivity through technology generation, experimentation, and diffusion, the development of the agriculture sector is constrained by a lack of actors involved in value addition practices (ICRA 2010).

Most of the stakeholder organizations are very much interested in increasing agricultural production and productivity through generating, disseminating and supplying agricultural technologies/inputs (Figure 3). Others are interested in protecting the environment, increasing income of farmers, building their capacities and providing quality services to farmers (ICRA 2010).

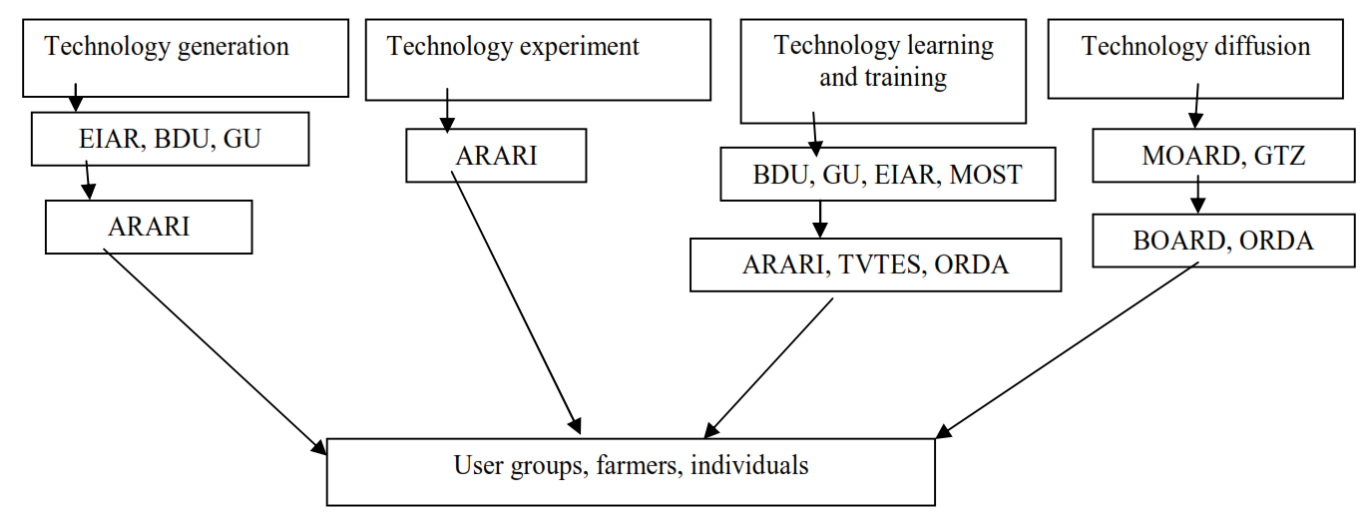

Figure 3. The level of stakeholders involved in technology generation in Amhara Region from national to regional level 


\section{TROPICAL DRYLANDS}

Volume 2, Number 1, June 2018

Pages: 18-27

\section{Experience in linking stakeholder organizations in Amhara Region}

Technology generation as the main component of technology development and research coordination was started in the country in the 1960's (EARO 1998). Technology transfer and linkage remained as peripheral responsibilities. In addition, poor participation of farmers and other actors in the platforms, absence of decision making power of the platforms due to lack of legalized authority, poor documentation, lack of clarity in roles and responsibilities given to stakeholder organizations, lack of a monitoring and evaluation system, lack of incentivesespecially for facilitators, lack of institutional memory in the stakeholder organizations and in the platforms because of high turnover of staff and committee members, poor coordination/facilitation, professional bias and continued topdown approach were serious problems observed in the efforts of technology transfer and linkage practices.

Reasons for poor institutional linkage are weak management capacity, inappropriate organizational structure, unfavorable reward systems, constraints on time and money, inappropriate planning, little or no monitoring and evaluation of the process of interaction and different organizational cultures, expectations and operating procedures. The weaknesses of earlier platforms were transferred to the next generation mainly due to the fact that new platforms were created without due evaluation of previous ones. Hence, any attempt that wishes to improve linkages and enhance multi-stakeholder rural innovation process in Amhara Region should consider and solve the problems indicated above but also strengthen existing and/or new platforms (e.g. Farmers Research and Extension Groups and ARDPLAC) (ICRA 2010).

\section{Agricultural research and extension linkages in the Amhara Region}

The term linkage is a broad range of collaborations and exchange of useful information among all actors of the technology generation, dissemination, and utilization system. Earlier empirical studies in developing countries have identified weak links between research and extension as the major factor limiting the flow of information, knowledge, useful new technologies, and resources among actors in the technology-delivery-utilization system and recommend measures to overcome the widely acknowledged weaknesses (Belay 2002; Anderson and Feder 2004).

Linked with the country's first Growth and Transformation Plan (GTP I), which was launched in 2010, the issue of research-extension linkage has received momentum. The plan targets the use of improved agricultural technologies along with transformation of the national agricultural technology delivery mechanisms. The national seed system is mainly considered as one of the key interventions in the transformation of the agricultural sector and also to achieve the target of doubling agricultural production by 2015 (MoFED 2010). This requires designing and implementing new and strengthening previous approaches in the agricultural research and development endeavors to ensure improved availability of agricultural technologies along with timely delivery to end users, farmers, and pastoralists.
E-ISSN: 2580-2828

DOI: $10.13057 /$ tropdrylands/t020104

All the necessary organizations and support services related to the generation of knowledge and technology, input delivery, advisory service, and marketing and credit services are in place. But these actors all function in a largely uncoordinated and fragmented manner. According to Havelock (1986), cited in Kassa (2008), coordination or linkage symbolizes two systems connected by messages to form a greater system. Agricultural research and extension are examples of two systems that can be linked by information flow and feedback (Munyua et al. 2002). Setting up the institutional linkage to foster proper information flow and effective collaboration is the most serious institutional problem in developing research and extension programs. The linkage between research and extension systems plays a significant role in the generation and dissemination of appropriate technologies. Strengthening research and extension linkages must mean cultivating greater and more effective interaction among the stakeholders in the agricultural sector. Past efforts and the current status of linkage between agricultural research and extension, as well as among the whole range of actors involved in agricultural commodity value chains in Ethiopia, with a focus on the Amhara Region.

\section{Technology adoption in Amhara Region}

Feed chopping technology adoption

Traditionally, the farmers provide their animals with all feeds without chopping. Maize stalk, the major feed in the areas, is given to the cattle as it is and sometimes little chopping is done. It actually results in great wastage but it is used for energy. In case of chopping of maize stock, it takes 2-3hrs to chop a feed sufficient for four cattle. In general, it has a great contribution since it reduces volume for both transportation and piling. The technology is best suited for transportation of feed. However, they indicated the need to create awareness to the larger community during grass harvesting, create conditions where community piling could be done in a specific place, continuous monitoring, and evaluation by local experts (Dagninet Amare et al., 2016).

\section{Milk churns technology adoption}

The horizontal churn is preferred for reduction of labor (tiresome) and possibility to be handled by even the men and young family members (Figure 4). Reduction of burden on women as in traditional methods is preferred as the women who would properly do that and its capacity to separate more butter than the traditional methods as other benefits of the technology. The reason for better production of butter is attributed to rotation of the whole milk at the same time that is not possible in traditional systems. The farmers confirmed that churn operation is simple. Further, the most vital advantage of churn is enabling extraction of butter that is marketed easily than milk. This is very crucial especially during fasting days and months where milk is mostly wasted (Dagninet Amare et al. 2016). The quality of butter extracted using modern churn is thought better as the churning leads to better drying. It takes on average $38 \mathrm{mins}$ and $23 \mathrm{mins}$ to extract butter using the modern churner for milk of same size, summer, and winter. 


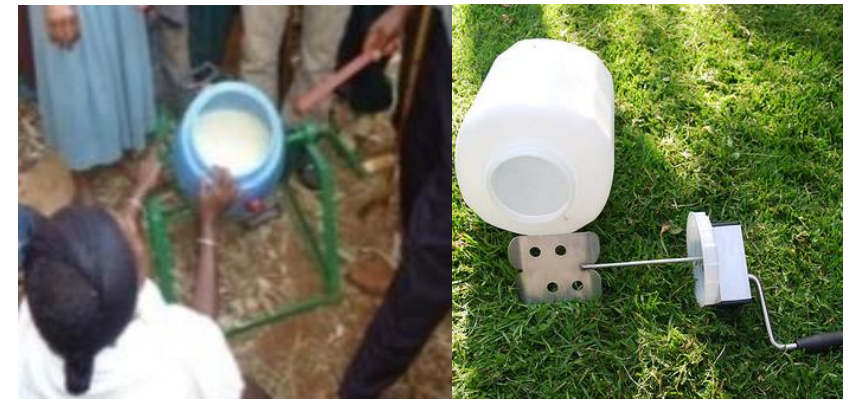

Figure 4. Milk churn technologies

\section{Adaptive research to link research, extension and rural households for technology adoption}

Given the high variability of agro-ecological zones, risk, and resource constraints facing rural households, there is a need for adaptive research that takes into account the diversity of conditions facing rural households. Establishing systematic linkages between research, extension, and rural households is an effective means of generating technologies appropriate for these conditions. Researchers must have frequent feedback about what is and is not working in terms of benefits to farmers. Rural household members and extension agents can not only provide that information but are often the best source of ideas on how to adapt technology to local conditions. In addition, linkages involving rural households to set the research agenda help to ensure that new technologies are not only technologically viable but indeed address priority problems as perceived by rural households who are the ultimate users of technological solutions (ICRA 2010).

\section{AGRICULTURAL TECHNOLOGIES UNDER CONSIDERATION}

DeJanvry et al. (2011) stated both yield-increasing and cost-saving technologies are reducing the costs per unit of outputs. Yield-increasing technologies also allow for higher gross output if some inputs (especially land) are limited. Examples of yield-increasing dairy technologies include improved dairy breed and improved feed. Costsaving technologies may also include new dairy technologies that require fewer complementary inputs and cultivation practices that could produce equal results with less effort. Risk-mitigating technologies help to minimize the risk of very bad outcomes in times of unfavorable environmental conditions, but might not increase yield in times of favorable conditions. Some examples of riskmitigating technologies and conditions under which their impacts might not be observable are drought-and diseaseresistant cattle breed and livestock vaccines inoculation. These technologies help increase the quality of outputs in some respect even if yield does not improve. These types of technologies differ from the others in that the main benefits accrue to consumers. The impact of qualityimproving innovation is difficult to evaluate, in part because the channel of transmission from the availability of the new variety to the manifestation of benefits involves several actors. Adoption by consumers requires that producers have already adopted and produced the variety so that it is available to consumers, and that consumers have chosen to consume it (DeJanvry et al., 2011).

\section{OPPORTUNITIES TO IMPROVE THE PERFORMANCE OF AGRICULTURE}

The existing government policies are considered to be in line with the CSOs and NGOs goals to bring about the smallholder farm development and ensure food security of the rural households. Over the last few years, the government's agricultural development strategy emphasizes market orientation and commercialization of smallholder agriculture. Hence, interventions that would support market creation and enhance market access have gained attention. Some NGOs have started to facilitate market functioning and value-adding through farmers' cooperatives and unions. The fact that there is a huge gap between the need and level of technology used by the smallholder farmers means that there is an opportunity for CSOs to operate towards filling this gap. It implies support for technology multiplication and training of farmers on how to multiply selected and adaptable agricultural technologies. Currently, although there is a high demand for improved agricultural technologies, the supply of inputs like improved seed does not meet the demand. Smallholder farmers can increase their income and food security if CSOs will support them to produce selected clean seeds and connect them to the market so that they can sell them (Berhanu et al. 2006). Market involvement increases the income opportunity of households and increases the adoption of agricultural and conservation technologies (Amsalu and de Graaff 2006). The positive association between poor access to market and adoption of improved breeds and feed is likely to be due to poorer households' access to NGO credit and extension programs in remote areas, which was the case also in the study by Benin et al. (2003). Improved access to irrigation through intervention in this area is another positive predictor of crop and livestock technology adoption (Wubeneh and Sanders 2006).

\section{MAJOR CHALLENGES OF POOR ADOPTION BY AGRICULTURE INDUSTRY OF TECHNOLOGIES}

The Ethiopian agricultural research system could not be as effective as expected for it has not been demand-driven and not able to solve the complex problems of the agricultural sector. It was indicated that due to lack of proper coordination among the institutions and organizations that provide development services for the sector and stakeholders at large, meaningful changes and improvement could not be attained (Berhanu et al. 2006). The effective development of technology and dissemination of the knowledge/information was obtained from the research challenged by different factors. According to Day et al. (1994) lack of effective communication is among the major barriers in the execution of research, dissemination of results to the desired user, and effective application of the 
technology as proved by research. The absence of effective communication about the technologies might result in poor decision making, delay in the planned activities, and failure and deficiencies in the dissemination of research results thereby the technologies remain without use for the desired objectives/impacting the end user (Day et al.1994). This shows the importance of having strong linkage between the different information/knowledge system partners; having good linkage between stakeholders ensures the transfer of information and knowledge among the different stakeholders properly and helps to achieve the desired objective.

Weak link between research, education, and extension and also the contact these organizations have with farmers is among the main bottlenecks in agricultural technology development, transfer, and adoption level and thereby reduce the contribution of the technologies to development (Van Crowder and Anderson 1997). Government policy and organizational structure also affect the linkage between the different parties in the agricultural sector. This is because the different groups/members in the linkage/ information transfer system act in accordance with the policy. According to Van Crowder and Anderson (1997), interaction among different actors helps to produce better knowledge different from those produced by one actor alone. Moreover, Hall et al. (2001) suggested the need for collaborative relationships between public and private, and research and non-research organizations to assure successful technology development.

\section{CONCLUSION AND RECOMMENDATION}

From this review, it is possible to conclude that, a high rate of agricultural growth has far-reaching positive implications for economic development of low-income countries in terms of increasing employment and accelerating poverty reduction. The Government of Ethiopia draws up a long-term industrial strategy (Agricultural Development-Led Industrialization) in 1994. Increase agricultural output and productivity, increase industrial output and productivity and close input-output linkage between the two sectors are the core of Agricultural Development-Led Industrialization. Based on this review, it is concluded that strengthening the link between stakeholders, enhancing the innovation of the sector and involvement of professionals in the system are the basis to improve the efficiency of the system. Having a strong linkage between research, education, extension, farmer and other concerned stakeholders has the power to improve the performance of the agricultural system. Yet, collaboration among universities, research institutes, TVET colleges, and industries was weak.

Agricultural linkage encloses generating and transferring agricultural technologies to enhance productivity, reduce loss, and improve the livelihoods of beneficiaries as well as the country's economy. Technologies need to be properly packaged to meet the needs of the target clients and achieve the desired level of productivity. Linkages between major institutional actors in agricultural knowledge and information system are widely recognized as essential for an effective flow of technology and information between research, extension, and farmers.

Majority of the agriculture industries do not link with local agriculture research industries. Most of the agricultural technologies promoted through the extension system and adoption levels are far below the expectation. Agriculture research industries lack effective mechanisms of transferring their technologies to the end users. Most of the agricultural technology adoption was conducted focusing on a single commodity or technology, and do not consider the possible inter-relationships between the various practices and intensity of adoption of a package of technologies. Lack of responsible body to transfer technology and no attempt of impact assessment after technology is transferred to users are the major challenges. Existing poor linkage of agriculture-industries with local agriculture research industry is a serious constraint to the adequate growth of both agriculture and agro-industry in the country.

Factors constraining the linkage between stakeholders and technology adoption level of universities, TEVTs, agriculture research institutions and agriculture sector are wide ranging from poor linkage between stakeholders and weak involvement of professionals in the system. Weak link between research, education, and extension and the contact these organizations have with farmers is among the main bottlenecks in agricultural technology development, transfer and adoption level. Thus, several recommendations are suggested as follows. (i) There should be an action plan so as to effectively increase technology adoption and strengthen agriculture and industry in Ethiopia. (ii) Interorganizational linkages should be assessed to maintain better aspects and negotiate improvements in existing linkages, linkage mechanisms and develop new relationships. (iii) Establishing systematic linkages between research, extension, and rural households is an effective means of generating technologies. (iv) Further study of the linkages between agriculture and industry and agriculture and research industry is needed. (v) Impact assessment of the transferred technology needed to bring about on the user's livelihood and different feedback mechanisms can be used to do so. (vi) Therefore, strong university and research-industry linkage is required in the country.

\section{REFERENCES}

Admassie A, Asfaw A. 2004. The role of education on the adoption of chemical fertilizer under different socioeconomic environments in Ethiopia. Agric Econ 30 (3): 215-228. DOI: 10.1111/j.15740862.2004.tb00190.x

Akalu T, Adgo A. 2006. An overview of Research Extension-Farmer linkage in Amhara Region: Challenge and opportunity Bahir Dar, Ethiopia.

Alemitu M. 2011. Factors Affecting Adoption of Improved Haricot Bean Varieties and Associated Agronomic Practice in Dale District, SNNPS. [Thesis]. Hawassa University, Hawassa.

Amsalu A, Graaff De.2006. Farmers views of soil erosion problems and their conservation knowledge at Beressa Watershed, Central Highlands of Ethiopia. Agric Human Val 23: 99-108. DOI: $10.1007 / \mathrm{s} 10460-005-5872-4$

Anderson JR, Feder G. 2004. Agricultural Extension: Good Intentions and Hard Realities. World Bank Research Observer 19 (1): 41-60. DOI: 10.1093/wbro/lkh013 
ATA. 2014. The new agricultural input sales system. Technical report. Ethiopian Agricultural Transformation Agency, Addis Ababa.

Belay K. 2002, Constraints to Extension Work in Ethiopia: The Insiders View. South African J Agric Exten 31: 63-79.

Belay K. 2003. Agricultural Extension in Ethiopia: The Case of Participatory Demonstration and Training Extension System. J Soc Dev Afr 18 (1): 49-83. DOI: 10.4314/jsda.v18i1.23819

Benin S, Ehui S, Pender J. 2003. Policies for livestock development in the Ethiopian highlands. Environ Dev Sustain 5: 491-510. DOI: 10.1023/A:1025737315629

Bertuglia A, Calatrava-Requena J. 2006. Factors Related to the Adoption of Good Agrarian Practices (GAP) in Plastic Covered Horticulture of Southeastern Spain. In: 2006 International Association of Agricultural Economists Annual Meeting, August 12-18, 2006, Queensland, Australia (No. 25545).

Berhanu G, Hoe Kstra D, Azage T. 2006. Commercialization of Ethiopian agriculture: Extension service from input supplier to knowledge broker and facilitator. IPMS (Improving Productivity and Market Success) of Ethiopian farmers project working paper 1. ILRI (International Livestock Research Institute), Nairobi, Kenya.

Besley T, Case A.1993. Modeling technology adoption in developing countries. The American Economic Review, 396-402.

Day D, Dosa M, Jorgensen C. 1994. The transfer of research information within and by multicultural teams. Inf Process Manag 31 (1): 89-100. DOI: 10.1016/0306-4573(95)80009-I

Dagninet A, Menale W, Meseret T, Tegegne D, Awole M, Negesse Y, Dessie M, Giorgis MT. 2016. Integrating feeding and productivity: scaling out livestock input and output processing technologies for smallholders, Intl Multilingual J Sci Technol 1 (1): 59-65.

De Graaff J, Amsalu A, Bodna r F, Kessler A, Posthumus H, Tenge A. 2008. Factors influencing adoption and continued use of long-term soil and water conservation measures in five developing countries Appl Geogr 28: 271-280. DOI: 10.1016/j.apgeog.2008.05.001

DeJanvry A, Dunstan A, Sadoulet E. 2011. Recent Advances in Impact Analysis Methods for Ex-post Impact Assessments of Agricultura Technology: Options for the CGIAR. Report prepared for the Workshop: Increasing the Rigor of Ex-post Impact Assessment of Agricultural Research: A Discussion on Estimating Treatment Effects, Organized by the CGIAR Standing Panel on Impact Assessment (SPIA), 2 October 2010, Berkeley, California, USA.

Diederen P, Hans van M, Arjan W, Katarzyna B. 2003.Innovation adoption in agriculture; Innovators, Early adaptors and laggards, Wageningen University and Research Center, Netherlands.

Doss CR. 2006. Analyzing technology adoption using microstudies: limitations, challenges, and opportunities for improvement. Agric Econ 34: 207-219. DOI: 10.1111/j.1574-0864.2006.00119.x

EARO. 1998. Research-Extension-Farmers Linkage Strategic Document, EARO, Addis Ababa, Ethiopia.

Feder GRE, Zilberman JD. 1985. Adoption of agricultural innovations in developing countries: A survey. Econ Dev Cult Ch 33: 255-298. DOI $10.1086 / 451461$

Foster D, Rosenzweig M. 2010. Learning by Doing and Learning from Others: Human Capital and Technical Change in Agriculture. J Poli Econ 103: 1176-1209. DOI: 10.1086/601447

Gabre-Madhin EZ. 2001. Market institutions, transaction costs, and social capital in the Ethiopian grain market, Volume 124. Intl Food Policy Res Inst., Washington, DC

Getahun D, Mwangi M, Verkuijil H, Wondimu A. 2000. An assessment of the adoption of seed and fertilizer packages and the role of credit in smallholder maize production in Sidama and North Omo Zones, Ethiopia. EARO, CIMMYT, November 2000.

Hall A, Bocket G, Tylor S, Sivamohan MVK, Clark N. 2001. Why research partnerships really matter: innovation theory, institutional arrangements and implications for the developing new technology for the poor. World Dev 29 (5): 783-797. DOI: 10.1016/S0305750X(01)00004-3

Hall A, Rasheed S, Bezkorowajnyj P. 2007. Tools for diagnosis and Institutional Change in Innovation Systems: In reforming technical change: Livestock Fodder Scarcity Revisited as Innovation Capacity Scarcity. UNU-MERIT working paper series 2008-004. Maastricht Economic and Social Research and Training Centre on Innovation and Technology.United Nations University. Maastricht.

Hailu B, Abrha B, Weldegiorgis K. 2014. Adoption and impact of agricultural technologies on farm income: evidence from Southern Tigray, Northern Ethiopia. Intl J Food Agric Econ 2: 91-106. DOI: 10.22004/ag.econ. 190816
Hagmann J, Connolly M, Ficarelli P, Ramaru J. 2002. The Service Delivery Framework: understanding the development of service systems as a systemic change and negotiation process within and across three levels of demand and supply. Picoteam Ltd., Germany.

ICRA. 2010. Multi-stakeholder linkages in rural innovation process in Amhara region, Ethiopia. Working Document Series, 137. ICRA, Ethiopia/

ICARDA, FAO, AARINENA, CIHEAM. 1999. The national agricultural research systems in the West Asia and North Africa region. ICARDA, Aleppo, Syria.

Kaske D. 2007. Agricultural information networks of farm women and role of agricultural extension: the case of dale Woreda, Southern Nations Nationalities Peoples Regional State. [Thesis]. Haramaya University, India.

Keeley J, Scoones I. 2000. Knowledge, Power and Politics: the environmental policymaking process in Ethiopia. J Modern African Stud 38 (1): 89-120. DOI: 10.1017/S0022278X99003262

Kelsey J. 2011. Market inefficiencies and the adoption of agricultural technologies in developing countries.

Kosarek JL, Garcia P, Morris ML. 2001. Factors explaining the diffusion of hybrid maize in Latin America and the Caribbean region. Agric Econ 26 (3): 267-280. DOI: 10.1111/j.1574-0862.2001.tb00069.x

Koundouri P, Nauges C, Tzouvelekas V. 2002. Endogenous technology adoption under production risk: theory and application to irrigation technology. Working Papers 0411. Department of Economics, University of Crete, Greece.

Kassa B. 2003. Agricultural extension in Ethiopia: the case of participatory demonstration and training extension system. J Soc Dev Afr 18 (1): 19-84. DOI: $10.4314 /$ jsda.v18i1.23819

Kassa B. 2008. Linkage of higher education with agricultural research, extension and development in Ethiopia. Higher Educat Pol 21: 275299. DOI: $10.1057 /$ palgrave.hep.8300139

Maredia MK, Minde IJ. 2002. Technology profitability and agricultural transformation: Concepts, evidence, and policy implications. Perspectives on agricultural transformation: A view from Africa. Ethiopian Agricultural Transformation Agency, Addis Ababa.

MoFED. 2010. Growth and Transformation Plan 2010/11-2014/15. Ministry of Finance and Economic Development, Addis Ababa

Munyua CN, Adams PF, Thomson JS. 2002. Designing Effective Linkages for Sustainable Agricultural Extension Information Systems Among Developing Countries in Agricultural research and extension linkages Sub-Saharan Africa. Proceedings of the 18th Annual Conference of the Association for International Agricultural and Extension Education, Durban, South Africa.

Rogers EM. 1995. Diffusion of Innovations. 4th ed. Free Press, New York Shiferaw BA, Okello J, Reddy RV. 2009. Adoption and adaptation of natural resource management innovations in smallholder agriculture: reflections on key lessons and best practices. Environ Dev Sustain 11: 601-619. DOI: 10.1007/s10668-007-9132-1

Solomon A, Bekele S, Franklin S, Mekbib G. 2011. Agricultural technology adoption, seed access constraints and commercialization in Ethiopia. JDAE 3: 436-447. DOI: 10.1016/j.foodpol.2012.02.013

Solomon A, Shiferaw B, Simtowe F, Lipper L. 2012. Impact of modern agricultural technologies on smallholder welfare: Evidence from Tanzania and Ethiopia. Food Policy 37: 283-295. DOI: 10.1016/j.foodpol.2012.02.013

Stiglitz, Joseph. 2009. "Report of the Commission on the Measurement of Economic Performance and Social Performance," Paris

SAMY MM. 1998. Constraints to effective transfer of corn technology as identified by farmers in Menoufia Governorate, Egypt. Alexandria J Agric 43: 1-10.

Shahin ASA. 2004. Adoption of Innovations in Smallholder Buffalo Dairy Farms in the Menoufia Province in Egypt. [Dissertation]. Menoufia University, Egypt

Taffes AS, Dorosh P, Gemessa SA. 2013. Crop production in Ethiopia: Regional patterns and trends. Food and agriculture in Ethiopia. Prog Pol Challeng 74: 53.39.

Van Crowder L, Anderson J. 1997. Linking research and education: why is the problem so persistent and pervasive? J Agric Educat Exten 3 (4): 241-249. DOI: 10.1080/13892249785300061

Wubeneh NG, Sanders JH. 2006. Farm-level adoption of sorghum technologies in Tigray, Ethiopia. Agric Syst 91: 122-134. DOI: 10.1016/j.agsy.2006.02.002

Zaltman G, Duncan R, Holbeck J. 1973. Innovations and Organizations. John Willey \& Sons, New York 